\title{
Construction of Personalized English Teaching Model Driven by Big Data
}

\author{
Zhang Xiaohui \\ School of International Education, Shan Dong Xiehe University, Shandong, China, 250109
}

Keywords: big data; personalized English; teaching mode

\begin{abstract}
With the acceleration of educational reform and the advancement of information-based education, the traditional teaching mode of English teaching in China has neglected the cultivation of students' individualized learning. In the era of big data, it is urgent to make corresponding reforms in personalized English teaching in China. Firstly, it introduces the meaning and basic characteristics of big data. Secondly, it elaborates the basic requirements of individualized English teaching. Then it analyses the impact of big data on individualized English teaching. On this basis, it puts forward the strategy of constructing individualized English teaching mode based on big data.
\end{abstract}

At this stage, China is in a big data era of information and knowledge explosion, and the long-distance technology exchange of mobile electronic devices and the Internet has also developed rapidly. In the era of big data, all data can be quantified as a huge advantage for us to learn knowledge, providing unlimited possibilities for creation. English teaching in China is facing more development challenges and opportunities due to the arrival of the big data era, but it also provides a huge space for the development of individualized English teaching. In addition, the development of individualized English teaching helps to solve the problems existing in English teaching in China. The problem. Therefore, this paper focuses on personalized English teaching based on big data to carry out research on teaching strategies.

\section{The Meaning and Basic Characteristics of Big Data}

Big data is also called huge amount of data, which comes from the article "Big Data Age". People have different opinions about its meaning. At this stage, people generally agree that the meaning of big data is to develop a new processing model to promote decision-making and insight, at the same time have the ability to optimize a large number of processes, improve the diversification of information assets and high growth rate. It mainly includes the following four basic characteristics: low value density, refers to the increasing number and types of information under large data, which leads to the decline of information identification and affects the value density; mufti-type refers to that users are not only users of information, but also publishers of information under large data, so the number and types of information are increasing constantly; fast change refers to large data. Under this condition, it can meet the user's data exchange needs in time and realize the timeliness of information. Large amount of data refers to the large amount of data can be stored in the era of big data, which embodies the characteristics of large amount of data and 
complete information.

\section{Basic Requirements of Individualized English Teaching}

\subsection{Developing Personality}

The main purpose of individualized English teaching is to develop students' individuality, promote students' physical and mental health, ability, knowledge and personality integrity, at the same time, cultivate students' innovative ability and independent consciousness, and increase students' life experience. It mainly achieves students' personality development by promoting self-transcendence, learning for application and potential development.

\subsection{Respect for Individuality}

Students' differences in learning individualized English are mainly reflected in the differences in quantity and quality: the differences in quantity refer to the differences in learners' learning level, learning ability and the speed and degree of knowledge reception; the differences in quality refer to the differences in learning styles caused by different learners' behavior patterns and the differences in learning caused by different physiological and psychological characteristics. Accustomed to different. Therefore, in the process of individualized English teaching based on big data, students' differences should be fully respected and students' differences should be correctly treated according to their differences. Differences, and then help students form their own way of thinking and learning mode. As shown in Table 1:

Table 1. Analysis of Differences among Universities

\begin{tabular}{|l|c|c|c|}
\hline & classification & SD & T \\
\hline \multirow{2}{*}{ learning environment } & Key universities & 3.6344 & 0.2234 \\
\cline { 2 - 4 } & Colleges and Universities & 3.4834 & 0.1845 \\
\hline \multirow{2}{*}{ Learner knowledge } & Key universities & 2.9793 & 0.2976 \\
\cline { 2 - 4 } & Colleges and Universities & 2.8604 & 0.2634 \\
\hline \multirow{2}{*}{ learning motivation } & Key universities & 2.8353 & 0.2106 \\
\cline { 2 - 4 } & Colleges and Universities & 2.8335 & 0.1801 \\
\hline
\end{tabular}

\subsection{Research on Personality}

When receiving external information stimulation, different individuals will produce different ways of solving problems, memory, thinking, attention and perception, which also makes learners form different styles and types of learning, which are mainly reflected in the differences of thinking mode, time preference, perceptual style, brain dominant hemisphere, perceptual channel, emotion and motivation. Studying learners' individual differences will help learners to understand and reflect on their own learning personality characteristics more profoundly, and then find a learning model that is in line with their own personality characteristics.

\section{The Impact of Big Data on Individualized English Teaching}

\subsection{Personalized English Learning Based on Big Data}

As shown in figure 2, a detailed analysis is presented below. 


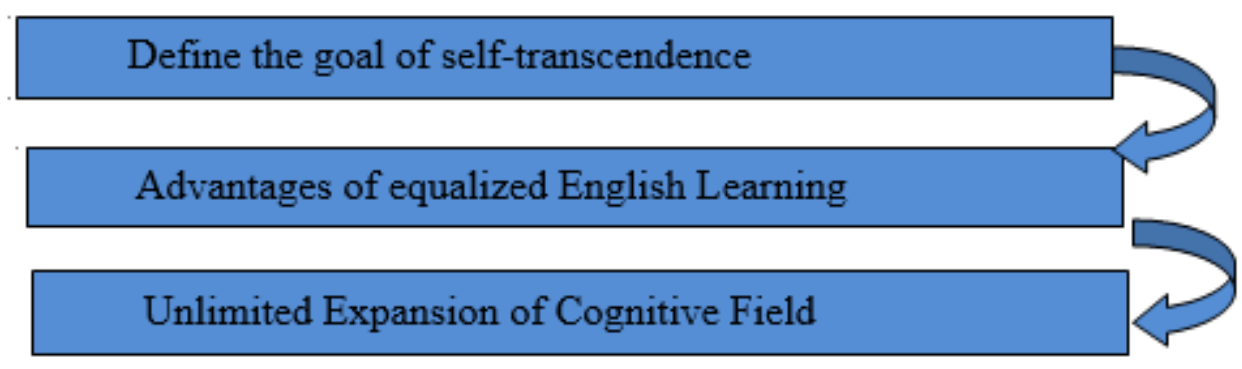

Figure 2. Personalized English Learning Based on Big Data

\subsubsection{Define the goal of self-transcendence}

Individualized English learning should put learners at the center of individualized English teaching, integrate students' own characteristics, design and formulate teaching tasks and teaching contents with pertinence and challenge, and then meet students' individual needs, realize students' self-dignity and self-respect, and form a certain sense of self-responsibility and self-learning consciousness. Effective mobilization of students' own learning motivation, promote the real occurrence and progress of classroom learning.

\subsubsection{Advantages of Equalized English Learning}

Individualized English learning based on big data grasps learners' learning ability and learning status by quantifying teaching data, and promotes the full use of teaching resources, teaching content and syllabus through the individualization of data.

\subsubsection{Unlimited Expansion of Cognitive Field}

Personalized English learning can also be achieved through the learning network platform. According to the differences of life experience, adaptability, interest and educational background of each student, the content of individualized English knowledge system can be reasonably planned. Then, through teachers' individualized guidance and students' self-discussion after class, the learning results can be shared, exchanged and exchanged in the learning space, and a three-dimensional English knowledge system can be constructed. Create a learning environment of individualized guidance, cooperative learning and self-exploration between students and students.

\subsection{The Impact of Big Data on Individualized English Teaching}

\subsubsection{Optimizes the Individualized English Teaching Model}

In the process of personalized English teaching based on big data, the communication process of learning interaction, management, resources, tools and objects belongs to an open teaching environment. Among them, the teaching objects are no longer controlled, thus increasing students' learning opportunities, enabling students to learn English knowledge online at any time and anywhere, actively carry out communication and communication between teachers and students, students and students, create a good interactive atmosphere, and stimulate students' enthusiasm and initiative in English learning.

\subsubsection{Provides Confirmation Teaching Resources and content}

Teachers should give full play to the advantages of network in the environment of big data, and 
then obtain vivid, authentic and vivid language teaching content, strengthen the resource richness of teaching resources and teaching content, so as to urge students to collect more information resources in the shortest time, and improve the quality and efficiency of learning.

\subsubsection{Enriches the form of teaching organization}

The form of teaching organization is no longer limited to classroom teaching, but also includes the use of network platform, which perfectly combines self-study, individual teaching and group teaching, enriching the organizational mode of English teaching.

\subsubsection{Constructing a Democratized Teacher-Student Relationship}

Under the big data environment, students can learn a lot of English information resources through the multimedia network, and at the same time, they can choose the learning mode, teachers, teaching content and teaching courseware according to their own needs. Under the current big data environment, teachers should become the collaborators and guiders in the process of students' individualized English learning, and build a harmonious and democratic teacher-student relationship with students, so as to fully stimulate students' interest in learning English and promote the implementation and implementation of individualized English teaching objectives.

\section{Individualized English Teaching Strategies Based on Big Data}

\subsection{Constructing a Diversified Teaching Evaluation System}

Building a diversified teaching evaluation system is one of the main means of personalized English teaching strategies based on big data. Teachers should pay attention to the observation of students' personality differences, discover and find flash points in students, and then analyze and evaluate students from multiple perspectives and levels. At the same time, teachers can organically combine teachers' evaluation with students' mutual evaluation and self-evaluation through students' evaluation.

\subsection{Forming a Personalized English Teaching Model}

Firstly, it applies the individualized mufti-mode of English teaching. In the process of designing individualized English teaching, we should rationally transform and transfer students' learning objectives according to their different learning motivations, and adjust teaching modes and contents to improve students' motivation to learn individualized English, promote the development of students' learning behavior, and further improve the teaching quality and teaching effectiveness of students' learning individualized English. Fruit.

Secondly, by using multimedia teaching based on network technology and computer technology as an auxiliary means, we can help the development of personalized English teaching based on big data. We should actively create an online education environment, make full use of the development opportunities provided by big data, and then provide some reference for students to choose learning content, learning mode, learning progress and so on. To clarify the teaching objectives of individualized English teaching is the starting point and destination of all activities in the teaching process, and plays an effective role in stimulating and guiding teaching activities. Teachers should fully consider these factors and individual differences before conducting individualized English classroom teaching, and reasonably design teaching objectives according to textbooks, so as to meet the needs of different students for individualized English teaching. At the same time, individualized English teaching modes and teaching objectives that meet the differences, feasibility and diversity 
should be formulated.

\section{Conclusion}

The popularity of the Internet and the advent of the era of big data have had varying degrees of impact on people's learning, life and production. China's education is inevitably impacted to some extent, which further promotes the innovation and reform of the construction of personalized English teaching model. The era background of big data provides a great space for the construction of individualized English teaching model in China, and effectively promotes the overall development of English teaching in China. Therefore, schools should seize the development opportunities provided by big data for individualized English teaching and actively change the individualized English teaching mode; teachers should also conform to the trend of development in the era of big data, make full use of multimedia technology to promote individualized English teaching and strengthen their own appeal and personality charm; college students should fully strengthen their creativity and initiative in English learning. Enthusiasm and enthusiasm, cultivate their own comprehensive ability.

\section{References}

[1] Yang Shijiazhuang, Bu Fa, H ou Ungainly. The Impact of the Big Data Era on the Public English Teaching in Higher Vocational Colleges and the Countermeasure Exploration --- Taking Fushun Vocational and Technical College as an Example [J]. Journal of Reckoning Teachers College: Social Science Edition, 2016 (5): 187-192.

[2] Wang Ding. Diversified and Ecologically-based English Course Setting for Higher Vocational Education in the Context of Big Data --- Taking Jungian Vocational and Technical College of Architecture as an Example [J]. Journal of Nan tong Textile Vocational and Technical College, 2014 (4): 116-120.

[3] Gan Zhengzhou. Constructing Big Data and Realizing Individualized Learning: A Case Study of the Construction of Learning Analysis System in Chengdu No.1 Middle School of Huang County [J]. China's Education Dramatization, 2015 (9): 81-85.

[4] New College English Teaching Model in the Era of Big Data [J] China Education Dramatization, 2016 (15): 80-82. [5] Deng Chechen. An Empirical Study on the Individualized Teaching Model of Good College English [D]. Wuhan: Master's Degree Thesis of Songhua University of Science and Technology, 2006. 